Determiners, Feline Marsupials, and the Category-Function Distinction: A Critique of ELT Grammars

\title{
Brett Reynolds
}

The concept of determiners is widely employed in linguistics, but mostly absent from English Language Teaching (ELT) materials (dictionaries, teacherreference books, and student-oriented texts). Among those employing the concept, there is near-universal confusion between determiners and pronouns, arising mainly from an analytical and terminological failure to distinguish consistently between the category (determinative) and the function (specifier). I criticize this situation and present linguistic evidence for a more consistent framework. I conclude by arguing that in language teaching and applied linguistics we rarely adopt advances from linguistics, not because they fail to meet some criterion of relevance à la Widdowson (2000), but simply because we are ignorant of linguistics in general.

Le concept de déterminants s'emploie largement en linguistique, mais il est très peu présent dans le matériel pédagogique pour l'enseignement de l'anglais (dictionnaires, manuels de référence pour les enseignants, manuels pour les étudiants). Parmi ceux et celles qui emploient le concept, il existe une confusion quasi universelle entre les déterminants et les pronoms. Cette confusion découle notamment d'une analyse erronée et d'une erreur terminologique faisant en sorte qu'on ne distingue pas toujours la catégorie (déterminant) de la fonction (spécificateur). Je critique cette situation et présente des données linguistiques qui plaident en faveur d'un cadre plus constant. Je conclus en affirmant qu'en enseignement des langues et en linguistique appliquée, nous adoptons rarement les avancées du domaine de la linguistique, pas parce qu'elles ne répondent pas à des critères de pertinence à la Widdowson (2000), mais parce que nous connaissons mal la linguistique de façon générale.

Smilodon is the scientific name given to a saber-toothed cat that ranged throughout the Americas between 10,000 and 2.5 million years ago. As a Felidae, it belongs to the same family as tigers, cheetahs, and domestic cats. It was an apex predator that used its long canines to puncture and rip the throat of its prey instead of crushing the windpipe as do modern cats. How- 


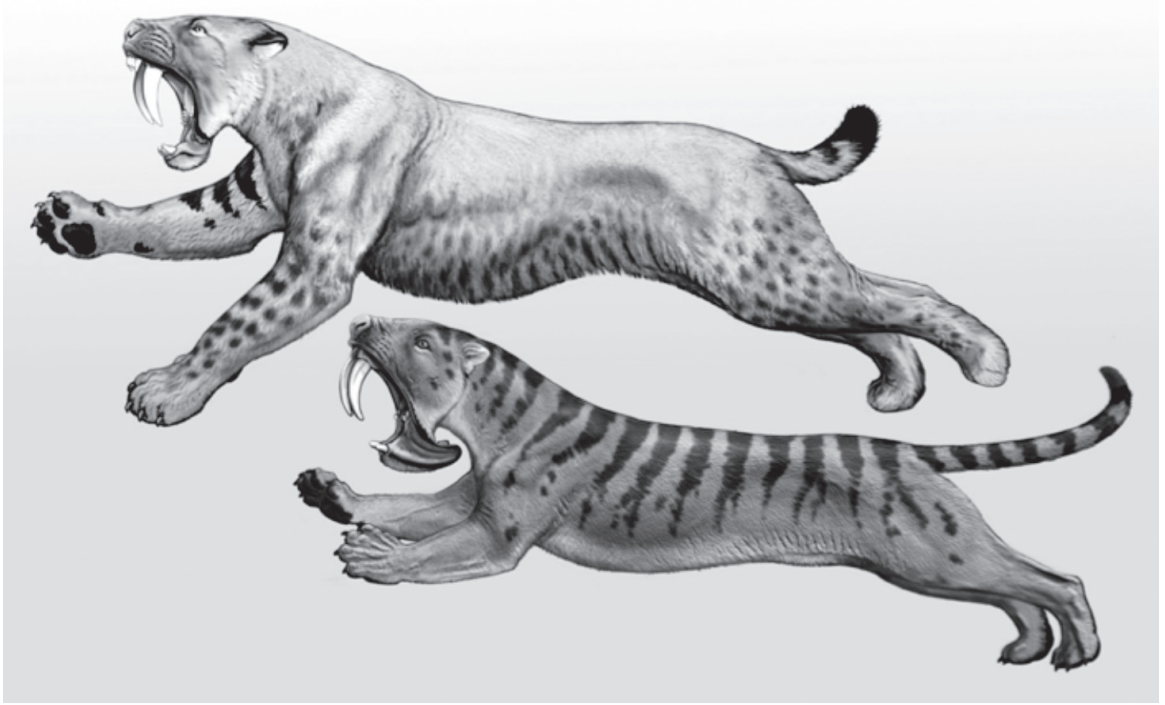

Figure 1. Smilodon (above) and Thylacosmilus (below) were remarkably similar in appearance and approaches to hunting (Zimmer, 2010). (C) Carl Buell (image used with permission).

ever, this strategy was not unique: it was shared by a strikingly similar saber-toothed predator, Thylacosmilus, which lived in South America from 3-10 million years ago (Churcher, 1985). These predators not only shared similar strategies and ecological niches, but also possessed remarkably similar physical characteristics, as shown in Figure 1.

Based on their similar morphology, hunting styles, and roles in the ecosystem, it would be tempting to classify these two predators as belonging to the same family. But far from being a feline, Smilodon was not even a placental mammal. Belonging to the order Sparassodonta, it was more closely related to opossums than to cats (Zimmer, 2010); classifying it as a cat would be a mistake, but justsuch a mistake is widespread in English-Language Teaching(ELT) materials, which regularly misclassify words based on their functions. Onearea wherethisis particularly egregious is in the categorization of certain pronouns as determiners and certain determiners as pronouns.

\section{The History of Determiners in ELT}

Although linguistics has seen many changes in the last century, one obvious change is in how it deals with words like the, this, many, every, and certain. Traditional grammar categorizes these as articles, pronouns, ${ }^{1}$ and various types of adjectives, but many modern analyses bring them together in one category (i.e., class, e.g., noun, adjective, verb). Palmer (1924) was the first to try to corral this 
group of hitherto heterogeneous English words by adopting a concept from French grammar.

To group with the pronouns all determinative adjectives (e.g., article-like, demonstratives, possessives, numerals, etc.), shortening the term to DETERMINATIVES [small caps added] (the "déterminatifs" of the French grammarians) firstly because there are divergent opinions as to whether they are adjectives or pronouns, and secondly, because most of the members of this category may be used indifferently as pronouns or as modifiers of nouns. (p. 24)

Bloomfield (1933) introduced the slightly different term determiner into English linguistics when he wrote,

Our limiting adjectives fall into two sub-classes of determiners and numeratives ... The determiners are defined by the fact that certain types of noun expressions (such as house or big house) are always accompanied by a determiner (as, this house, a big house). (p. 203)

These descriptions suggest that the authors are describing a category of words analogous to noun, adjective, and preposition, but although Palmer (1924) explicitly calls determinatives a category and recognizes their various functions, he also says that they may be used as modifiers (a FUNCTION, e.g.,sUBJECT, COMPLEMENT, MODIFIER) and pronouns (a category).

To use another animal analogy, Palmer's (1924) statement is equivalent to saying that dogs can be used as pack animals (as in the Arctic) or as cats. This is clearly an absurd statement. What is intended is that cats (a category) are often used as pets (a function) and that dogs often perform the pet function just as cats do. Palmer's wording (i.e., "used as ...") makes it unclear whether he intends a functional or categorical term, but the distinction is important.

To gauge the extent to which ELT materials have taken up this idea of determiners, I assembled a convenience sample of ELT books dealing with grammar from my personal library, my college library, and two central public libraries, books that employ terminology such as noun, object, tense, and plural. I also included books that I could find through a Google Books search and Amazon.com if they allowed searching of the text. This came to 71 items, including six language-learners' dictionaries (online versions of The Longman Dictionary of Contemporary English (LDOCE); the Oxford Advanced Learner's Dictionary (OALD); the Collins COBUILD Dictionary (COBUILD), which is no longer online; the Cambridge Advanced Learner's Dictionary (CALD); the Macmillan English Dictionary (MED); and MerriamWebster's Learner's Dictionary (MWLD) all accessed in August 2010), 17 texts intended for English-language teachers and 48 for English-language learners. 
I found that the idea of determiners is common to language-learners' dictionaries, appearing in five out of six, $M W L D$ being the exception. It is less common in materials for teachers, appearing in 11 out of 17 books examined, but receiving substantial attention in only five (i.e., Celce-Murcia and Larsen-Freeman's The Grammar Book, 1999: TGB; The Cambridge Grammar of English by Carter and McCarthy, 2006: CGE; Collins COBUILD English Grammar by Sinclair, 1990; Grammar for English Language Teachers by Parrott, 2010; and The Teacher's Grammar Book by Williams, 2005). Swan's (2005) treatment is characteristic of the other six: "Determiners come before adjectives in noun phrases, and show what part of a general class is being talked about. They include articles ('a,' 'the'), possessives ('my,' etc.), demonstratives ('this,' etc.) and quantifiers (e.g., 'each,' 'many,' 'all')" (p. 119).

Most materials for language learners, as opposed to materials for teachers, do not use the concept at all, although some mention the term briefly. The only exception that I discovered is a new series, Grammar and Beyond (Reppen, 2011), which devotes entire sections to determiners. In no publications, however, did I find a clear distinction drawn between a category and a function. (Hereafter I refer to the ELT materials that discuss determiners as "the determiners materials.")

\section{The Category-Function Distinction}

Generally, modern grammars distinguish both analytically and terminologically between the category of a grammatical unit such as a noun phrase (NP) and the syntactic function that it performs in a given context. Functions signify relationships between words, phrases, and clauses. Take the example the corporal goaded the beast. The corporal and the beast belong to the same category, NP, but they have different functions: The corporal is the subject, whereas the beast is the object. When we say that the corporal is the subject, we are describing its relation to the verb or to the clause that contains it. Categories, on the other hand, are sets of expressions that are grammatically alike in the language system. When we say that the corporal is an NP, we are saying that it is the same kind of expression as a man, the guy who wrote the editorial, a beautiful painting, the other four visitors from overseas, Sue, you, and so forth: These are all phrases ${ }^{2}$ (a unit intermediate between word and clause) consisting of a noun as HEAD (i.e., the most important element) alone or accompanied by various elements subordinate to it.

It is also important to keep in mind that categories and functions are rarely monogamous. That is, they typically participate in many-to-many relationships. To return to the animal analogy, dogs function as pets, pack animals, guides, and even livestock; in the same way, adjective phrases function both as modifiers in NPs (e.g., a very stable bracket) and as complements in verb phrases (VPs; e.g., be very, very quiet), among others. And just as the pack animal function can also be performed by horses, camels, and 
elephants, the complement function can also be performed by an NP or a preposition phrase, as is the case with be a saint and give me a hand or it was in the corner. In sum, members of a given category are usually capable of realizing more than one function, and most functions can be performed by words or phrases from a variety of categories.

Although there are various theories of grammar, this distinction is acknowledged in almost all. In systemic-functional grammar (SFG), for example, Halliday and Matthiessen (2004) use the labels class-what I am calling category-and function, although their list of functions is quite different from that of traditional grammar. In an attempt to keep the two distinct, they even employ the convention of using lower-case labels for the classes and wordinitial upper case for the functions. This can be seen in their analysis of the famous jacaranda trees of Pretoria as: the (determiner/Deictic), famous (adjective/Post-deictic), jacaranda (noun/Classifier), trees (noun/Thing), of Pretoria (preposition phrase/Qualifier) (p. 39).

In the more specific caseunder consideration here, it is not clear whether Palmer thought of determinatives as a category, a function, or something in between, but modern linguistics recognizes them as both a category and a function. Unfortunately, there is a good deal of terminological variance. Huddleston (1984) uses DETERMINATIVEtorefertoaclassof wordsincluding the, this, many, and others, employing DETERMINER as the term for the function these words mostcommonly perform in NPs. In a Comprehensive Grammar of the English Language, however, Quirk et al. (1985) make exactly the opposite terminological choice. Meanwhile, X-bar theory uses DETERMINER for the class and SPECIFIER for the function (Radford, 2009). In this article,IuseDETERMINATIVE(likeADJECTIVE)forthecategoryandSPECIFIER(likeMODIFER)for the function, trusting that these two words are distinct enough not to be confused with each other. ${ }^{3}$ Along with these, I employ determiner when discussing a hybrid notion like Palmer's.

We need this distinction in discussing determiners, because again the relationship between functions and categories is not one-to-one. In the first place, most determinatives can occur in functions other than specifier. One example would be modifier, as in he wasn't that tall, we need this much, all around the house, is she any different, no worse, little better, the bigger it was, and so forth. Although we could classify these as adverbs, as Quirk et al. (1985) appear to do, ${ }^{4}$ Occam's razor urges another analysis. Rather than positing adverb alter egos for most determinatives, it is more parsimonious simply to allow that they commonly function as modifiers, a single rule with someexceptions. This is the approach taken, for example, in the Cambridge Grammar of the English Language (CGEL, Huddleston \& Pullum, 2002). Recall that it is normal for members of a category to perform multiple functions; the same should be expected of determinatives.

Conversely, and more importantly for this article, the specifier function is not always filled by determinatives; it can also be filled by embedded NPs, usually 


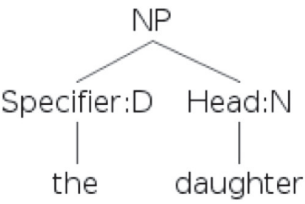

(a)

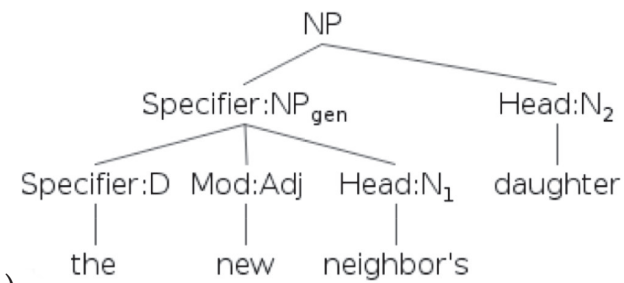

(b)

Figure 2. Two syntax trees showing the structure of an NP with a determinative (a) and a genitive NP (b), respectively, in specifier function. Function and category are shown in that order separated by a colon (e.g., Head:N). D = determinative and ${ }_{\text {gen }}=$ genitive.

GENITIVE $^{5}$ (e.g., Huddlesston \& Pullum, 2002; Quirk et al., 1985) as in the children's toys, Anne's grandfather, my job, and so forth. Compare, then, the structures for (a) the daughter and (b) the new neighbor's daughter in Figure 2. In (a) the is a determinative functioning as specifier to the head noun daughter. In (b) this same relationship exists between the and neighbor's, but there is a layering of NPs here such that here the entire genitive NP the new neighbor's functions as specifier to daughter.

Insistence on a one-to-one relationship between categories and functions would be problematic. It would lead to claims along the lines of: linking verbs are always followed by adjectives, and therefore the underlined phrases in be a saint and it was in the corner from the examples above are functioning as adjectives. It would be ridiculous and confusing to be told that $a$ saint, clearly an NP, is at the same time an adjective. Yet this is analogous to what happens in ELT when it comes to determiners, because as far as I can discover, no published ELT materials explicitly recognize the specifier function.

\section{The Specifier Function}

CGEL (Huddleston\&Pullum, 2002)identifies thefollowing threedistinctiveproperties of the specifier function ${ }^{6}$ : (a) this function occurs only in $\mathrm{NPs}^{7}$; (b) semantically, as the label suggests, specifiers typically servetospecify theNP as DEFINITE or INDEFINITE; and (c) in NPsheaded by singular countablecommonnouns, aspecifier (definite orindefinite) is typically obligatory (also mentioned by Bloomfield, 1933, as noted above). Thus the underlined NPsin the following examples are ungrammatical because the specifier is missing, not because "the article" is missing, although in some cases an article would function as specifier: ${ }^{*}$ idea is to protect consumers, ${ }^{*}$ I saw picture, ${ }^{*}$ do it way. Specifiers can be added to plural nouns and uncountable senses of singular nouns, but they are rarely syntactically required in such cases. 


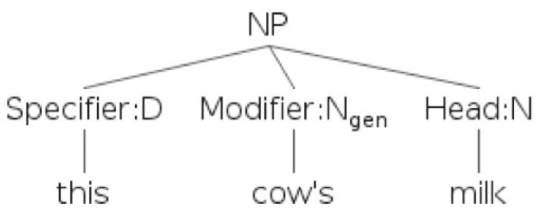

(a)

Figure 3. Syntax trees showing two possible interpretations of this cow's milk. In (a), the genitive functions as a modifier, whereas in (b) it functions as a specifier.

The specifier function is mostly realized by determinatives ${ }^{8}$ or genitive NPs, as in the woman's face, but not all genitives are specifiers; the genitives in, say, cow's milk and an old people's home are modifiers, not specifiers. Note that these genitives do not mark the noun phrase as definite. Cow's milk is indefinite, and we can add a specifier to give a definite noun phrase like this cow's milk (i.e., "the cow's milk I have here"; in the sense "the milk of this cow," this cow's is a genitive NP functioning as a specifier; see Figure 3).

Of course an old people's home is marked as indefinite by the specifier an. Furthermore, a few kinds of non-genitive noun phrase can function as specifier (e.g., What size shoes do you take?); in such cases the larger noun phrase is marked as indefinite. Finally, certain kinds of preposition phrase (e.g., up to 200 words) can also function as specifier in indefinite noun phrases (Huddleston \& Pullum, 2002).

\section{The Determinative Category}

Determinatives are for the most part individual words. Also included are a small number of complex determinatives, more or less fixed expressions that behave for the most part like single words such as a few and a little. They generally have the following properties.

1. They cannot combine with the or $a$, or with each other (except in coordination).

2. They can combine with a singular count noun to form a grammatical noun phrase.

3. They can occur asheads in the partitive construction(i.e.,inNPs with the form: HEAD + of + DEFINITE NP). ${ }^{9}$

I examine these three tests in turn.

Test 1: No combination with the or a. The items that satisfy this test, together with the and $a$ themselves, constitute the central core of the determinative category and are listed in Table 1. 
Table 1

Determinatives Passing Test 1

\begin{tabular}{lcccc}
\hline a & a few & a little & another & any \\
each & either & enough & every & much \\
neither & no & some & that/those & the \\
this/these & we/us & what(ever) & which(ever) & you \\
\hline
\end{tabular}

Leaving aside a few coordinations (e.g., each and every move, this or that circumstance), these items are mutually exclusive: standard English does not allow *the a generation, "the every move, *any much milk, "this enough milk. ${ }^{10}$

By this test, relative and interrogative what are determinatives, but not exclamative what, which can combine with a as in What a great idea it was! This what does not satisfy any of the tests and is best analyzed as an adjective like such in such a great idea. We/us and you are determinatives in expression such as we teachers, you students; elsewhere, of course, they are pronouns. A few and a little are complex determinatives and are best treated as single items rather than as a combination of $a$ and few/little, because elsewhere these have a negative meaning ("not many/much"), which is absent from the complex forms.

Test 2: Combination with singular count nouns. As observed above, singular count nouns cannot normally appear alone as head of a noun phrase: You cannot have ${ }^{*}$ Car turned left. Such nouns must normally occur with a specifier, typically a genitive noun phrase (e.g., Lean's car turned left) or a determinative. The determinatives that function as specifiers for singular count nouns are:

1. any of those in Table 1 except: (i) a few, a little, enough, much, we/us, and you, as these occur only with plural or non-count nouns; (ii) relative what.

2. one (e.g., One car turned left).

3. last and next used with temporal nouns (I'll see you next week, but not * ${ }^{*}$ 'll see you week or *I'll see you following week). Last and next here contrast with the uncontroversial determinative this. Elsewhere, they are adjectives and do not satisfy the test (e.g., ${ }^{*}$ Next car turned left).

Test 3: Occurrence in the partitive construction. We are concerned here with noun phrases like any of the boys, some of his milk, each of these tasks. Adjectives cannot occur in place of determinatives like any, some, and each in this construction: *Happy of the boys, "white of the milk, "very important of the documents. ${ }^{11}$ Some nouns can occur in this construction (e.g., Part of the building collapsed, Pieces of the bicycle were scattered all over the floor), but nouns are easy to distinguish from determinatives on other grounds. Words admitted into the determinative category by this test but not already covered by the first two tests are shown in Table 2. 
Table 2

Words Admitted Into the Determinative Category by Test 3

\begin{tabular}{lcccc}
\hline all & both & certain & few & little \\
many & more/most & several & sufficient $^{\text {a }}$ & various $^{\text {a }}$ \\
two, three, four, etc. (the cardinal numerals) & & \\
\hline
\end{tabular}

${ }^{a}$ Examples like various of the meanings are not uncommon, but neither are they universally accepted.

\section{Determinatives versus Pronouns}

Although confusion inELTmaterials aboutdeterminersis not limited to confusion with pronouns, ${ }^{12}$ this is the focus here. These two categories are confused in two main ways. First, all determiner materialsincludein the category of determinatives the words my, your, her, our, and their, together with his, its, and whose when used like the first five before a noun. I refer to these here as "the my set" and the morphologically related mine, yours, hers, theirs, his, its, and whose as "the mine set." Second, most ELT materials consider words like some, neither, more, and both to be pronouns where they are used independently of a noun (e.g., I have some) neither/more/both). I deal with these in order. ${ }^{13}$

\section{Why the My Set Are Not Determinatives}

In traditional grammar, there was disagreement as to whether the my set were adjectives or pronouns; and in modern work disagreement is equivalent as to whether they are determinatives or pronouns. ${ }^{14}$ The "determiners materials" universally classify the my set as determiners (i.e., determinatives). This includes all the dictionaries, the teachers' references books, and the students' textbooks. TGB (Celce-Murcia \& Larsen-Freeman, 1999), for example, categorizes the my set as "determiners" (p. 19). However, on page 297, it presents a hierarchical arrangement of categories in which personal pronouns are divided into subject, object, possessive, and other, with the possessive subcategory then divided into "determiners" (the my set) and pronouns (the mine set) as shown in Figure 4.

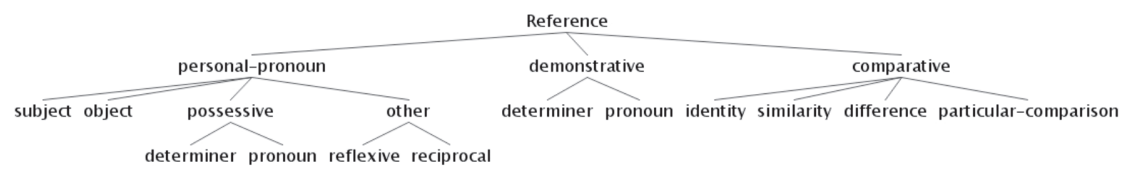

Figure 4. The hierarchical organization of reference topics in TGB (p. 297). From CelceMurcia/Larsen-Freeman. The Grammar Book, 2E. (C) 1999 Heinle/ELT, a part of Cengage Learning, Inc. Reproduced by permission. www.cengage.com/ permissions 


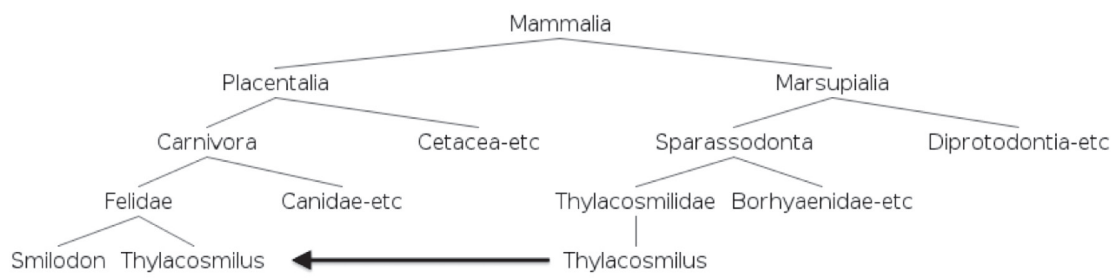

Figure 5. A pseudo-Linnaean classification with Thylacosmilus assigned to two distinct families.

This clearly poses a problem: determiner and pronoun are introduced as primary word categories (parts of speech) in Chapter 2, so having determiner as a subtype of pronoun is like accepting that placental mammals and marsupials are two sister subclasses of mammals ${ }^{15}$ only to classify Thylacosmilus as also belonging to a subgroup of placentals, as shown in Figure 5. Such an analysis would not be countenanced in biology, and neither should it be in ELT. Nevertheless, this mistake is repeated in Williams (2005), but with the categories reversed (i.e., possessive pronouns as a subclass of determiner) and in Parrott (2010), this time with the my set being called adjectives, a subtype of determiner.

This inconsistency is evident elsewhere in TGB (Celce-Murcia \& LarsenFreeman, 1999), where the words in question, generally called "possessive determiners," are also referred to as "possessive pronoun determiner(s)" (p. 302), "pronominal possessive determiners" (p. 314) and "possessive pronouns" (p. 316). Similarly, whose is called a "relative determiner" on page 581 , but is listed as a "relative pronoun" on page $582 .{ }^{16}$ Only if we separate a specifier function and a determinative category can these competing analyses be reconciled. Under this separation, the my set would be able to function as specifiers, but would belong to the pronoun category (a subset of $\mathrm{N}$ ) along with the mine set.

Moreevidence of TGB's (Celce-Murcia \& Larsen-Freeman) category-function confusion leading to a failure to distinguish pronouns logically from determinatives can be found in a table on page 298. The columns are headed "determiner function" (for the my set) and "pronominal function" (for the mine set), but as noted above, determiner and pronoun are for TGB, categories, not functions. ${ }^{17}$ Thus in Kim's copy was defective but mine was okay, for example, mine does not function as a pronoun; it is a pronoun. Its function is head of an NP, which in turn is functioning as subject of a clause. ${ }^{18}$

There are more basic reasons for treating the $m y$ set as pronouns. They are like pronouns in that they match the personal pronouns I, you, she, we, they, he, and it respectively in person, number, and gender and hence can be regarded as related to them inflectionally. Moreover, they are interpreted in the same way, generally deriving their interpretation from an antecedent. 
Finally, the my set has a function that is never performed by determinatives. She would object to my taking it (Huddleston \& Pullum, 2002). Uncontroversial determinatives do not appear in this construction, but genitiveNPs do. So we can replace my taking it with Jean's taking it or the children's taking it, but not with *the taking it, "nearly every taking it, or * no taking it.

It is clear, then, that my must be a pronoun in this case, and if it is a pronoun here, then it is also a pronoun in my car, for the difference is just a matter of function. The same forms occur in both constructions. To argue otherwise is to confound category and function. Thus the my set, like genitive NPs, generally function as specifiers, but they do not belong to the determinatives. They are pronouns.

\section{Why Determinatives are not Also Pronouns}

Traditional grammar distinguishes between the two instances of many in the team didn't have many great players left and the team had lots of great players, but there aren't many left, and the same applies to almost all the determinatives. In the first case, they are variously called "collective/limiting/determinative adjectives," and in the second case pronouns (Onions, 1971). As we see, some modern ELT materials reanalyze the first as a determiner, but they almost all retain the pronoun analysis of the second (Carter \& McCarthy, 2006; Celce-Murcia \& Larsen-Freeman, 1999; Parrott, 2010; Sinclair, 1990). To describe the difference in our terms, the first is specifier to a following head-noun, whereas the second is itself the head, ${ }^{19}$ these are differences of function, not category. ${ }^{20}$

Perhaps the most straightforward piece of evidence against analyzing much, many, few, and little as pronouns is that they accept modification by very in either function (specifier: not very many great players were left; head: not very many were left). Prototypical pronouns do not ("not very they were left). Another is the basic characteristic of pronouns: they "replace nouns and noun phrases" (Celce-Murcia \& Larsen-Freeman). In the example the team had lots of great players but they don't have many left, we interpret they as "the team." Those who adopt the pronoun analysis for words like many argue that many similarly stands for many great players, so like they, it is a pronoun. However, this fails for the partitive construction: In many of the players, for example, many is head, but it cannot be replaced by many players: English does not allow * many players of the players. Nor can many be replaced by players or the players. In fact nothing will work here but many, making this fundamentally unlike typical pronouns. The way to handle determinatives like many above is as a determinative in all three examples, but functioning sometimes as specifier (in There aren't many copies left) and sometimes as head (in there aren't many left and many of the copies).

In sum, categorization must consider all relevant characteristics, not simply the most obvious. Otherwise, we risk placing Thylacosmilus in the feline 
family because it looks and hunts like a feline, overlooking the fact that it bore relatively undeveloped joeys that further developed in a pouch.

\section{Conclusion}

Ifind that apart from dictionaries and a few teachers' references, current ELT materials generally treat words like the, this, some, many, either, and each as grammar texts did before Palmer (1924) and Bloomfield (1933). In so doing, they fail to present them as a single category of words with shared characteristics. Materials taking a post-Palmerian position are unclear on the differences between determinatives and pronouns, probably because they have no concept of specifier. This in turn is probably because of the failure to maintain consistently the categoryfunction distinction.

What does it matter that we in ELT might call my a determinative and many a pronoun, or that we hew to frameworks largely left behind by linguists? One might equally ask, "What does it matter that we classify a beast from the Pliocene as a feline even though it is more closely related to the kangaroo?" or "Why not call any dependent after a linking verb an adjective?" One simple answer is accuracy, academic integrity, and professionalism.

TESL struggles to be recognized as a profession. TESL Canada Journal even went so far as to dedicate an entire issue to the problem (Mathews \& Chuntian, 2004). Progress has been made in terms of certification standards. The fact that we think a clear understanding of grammar is essential to being a good teacher is evident in that TESL certification courses all require instruction in grammar. That we would then allow those classes to present content more than half a century out of date completely undermines the purpose. In examining ELT's struggle for professional status, Breshears (2004) observes that "the university system does not always value our epistemology" (p. 34). Quite so! Biologists know the difference between cats and marsupials. Chemists no longer talk of phlogiston, geologists have a deep understanding of plate tectonics, Freudian psychoanalysis does not dominate departments of psychology, and what in English departmentsis often simply called theory would hardlybe recognizable to 19th-century literary critics. By and large, these advances are even reflected in what is taught in elementary and secondary schools. In such a world, how can language teachers who cleave to incoherent, outdated grammars expect to be taken seriously?

Language classes commonly employ informative texts about topics ranging from crop irrigation to Canadian folk singers. Although learning about Gordon Lightfoot is presumably not the central purpose of such classes, any teacher would strive to present the information accurately. A textbook in which Lightfoot is said to be born in 1968 in Bristol, England, on one page and reported to be a 73-year old native-born Canadian on another would swiftly be corrected. Any teacher who employs grammar, whether for instructional purposes or just 
for raising awareness, should be equally concerned about the accuracy of the grammatical description.

Widdowson (2000) has argued that hesitance to introduce new ideas from linguistics into the classroom is positive. It does not

betoken a conservative allegiance to outmoded ideas or a stubborn refusal to countenance change, as has sometimes been suggested. Rather, it is an effort to refer these descriptive developments to applied linguistic principles by subjecting them to critical appraisal, so as to establish criteria of relevance. (p. 8)

Yet in this case, there is no evidence of such critical appraisal. Our field has not digested the fruits of the linguists and found them irrelevant. Wehave not chosen to avoid the idea of a specifier function on principle, finding it perhaps too complex. Nor have unsuccessful efforts been made to find how to bring a consistent category-function distinction to the classroom. To appraise something critically, we need to understand it, and in this case the evidence suggests that we do not. ELT grammars have failed to present a clear, coherent picture of determiners, and teachers and writers of materials have, perhaps as a result of this confusion, avoided the idea.

Although I focus here on determiners, our confusion is broader. We commonly talk of prepositions "functioning as" adverbs, nouns "functioning as" adjectives, and verbs "functioning as" nouns. Admittedly, linguistics and otherdisciplinesare not immune to incoherent ideas, but this does not take away from the messiness of the approach or excuse us from considering newer, more consistent, and more parsimonious frameworks. Infact, Widdowson (2000) went on to say how important it is "that we should take new modes of description, and their findings, into account in the design of language instruction" (p. 8). What we do, he says, "has to belinguistically informed without being linguistically determined" (p.23). Why, then, are we so uninformed about linguistics? Why are major linguistics journals like English Language and Linguistics and comprehensive grammars such as CGEL (Huddleston \& Pullum, 2002) almost never cited in the ELT literature these days? Thisblindnesstoadvancesingrammaticaldescriptionisnotnew. Cookmadesimilarobservationsin 1989, and Halliday, McIntosh, andStrevens(1964) werearguing for better descriptions of language two decades earlier.

Establishing the relevance of theories, linguistic or otherwise, is difficult. It is hard to imagine what the discovery and classification of extinct organisms could haveto do with geology, butfinding fossils of marsupialsinSouth America as well as in Australia was part of the evidentiary case that led to the acceptance of plate tectonics in themid-20th century (Colbert, 1974). Perhaps maintaining a consistent distinction between categories and functions in the ELT classroom will similarly prove valuable in ways that we cannot yet predict. ${ }^{21}$ For many years, direct grammar instruction has seemed relevant to some teachers and irrelevant to others. 
Now, however, a consensus appears to be forming that it is useful (Ellis, 2006), a consensus that has taken many years of research to establish. It is worth considering how this research program might have developed if students had been taught a more coherent grammar, rigorously distinguishing categories from functions. Perhaps consensus would have been easier to establish. It is also interesting to think how other research might have differed: would findings about the order of acquisition of pronouns(Ellis, 1994), say, or the valueof explicitcorrection(Van Beuningen, DeJong, \& Kuiken, 2012) change depending on whether pronouns were carefully distinguished from determinatives? Abettergrammarmightchangehow we look at language-learning, not just how we look at language.

There is also relevance in day-to-day teaching. Obviously, most of us find both categories and functions relevant. I know of no grammar book that speaks of nouns but not subjects, verbs but not objects. These interrelated systems of category and function allow us to provide descriptions with various levels of abstractness as needed. There seems to be a prima facie argument, then, for doing the same with determinatives and specifiers. Indeed, teachers may be hamstrung without these tools. I have seen instructors steeped in a current-traditional grammar struggle to explain the difference between, for example, the Schramm model and Schramm's model. Why can't we say *Shramm model or *the Schramm's model? Teachers who are familiar with the concepts of specifier and determinative should find such questions easy to answer: model is a singular countable common noun and, therefore, typically requires a specifier. The specifier function can be filled by a determinative the or genitive NP, Schramm's, but it can take only one, hence the ungrammaticality of the Schramm's model. In the case of Schramm model, the proper noun Schramm is functioning as a modifier, leaving the obligatory specifier function unfilled.

It also impinges on the examples that we present to our students. A teacher who lists I know most of the people with examples of personal pronouns such as I know them, is likely to raise questions about what that of the is doing there. This may even have some causal role in the common errors most of people and almost people. Better explanations and selection of examples better to exemplify categorically similar items may help students avoid or overcome such mistakes.

Admittedly, the detailed evidence and explanations provided above are not by any means simple, and yet students need not be burdened with the type of analysis presented here. It is aimed at authors of reference grammars, teacher trainers, and teachers themselves, all of whom should have a deeper understanding of how the system works. For most students, it may be as simple as having a list of determinatives to refer to or a dictionary that labels them correctly. Maintaining the category-function distinction and presenting such lists pose no particular burden to language-teachers. I suggest, then, that a system that distinguishes between determinatives and specifiers as set out above is a practical alternative to ELT grammar as well as being more accurate. 
These ideas have been with us for over 90 years, which is plenty of time to come to grips with them. If we want our students to be curious and proactive about learning the language, then we should ask no less of ourselves. It is not only incumbent on all teachers to strive for accuracy; it is unethical to "deliberately suppress or distort subject matter" (National Education Association, n.d.). ELT grammars are avoidable distortions and need to be replaced with better models. Suchmodels are readily availableif only we would avail ourselves of theminstead of foisting on students our version of the marsupial cat.

\section{Notes}

${ }^{1}$ In modern grammars, the pronoun is treated as a subclass of noun rather than as a distinct part of speech. Pronouns are like common and proper nouns in that they occur mainly as head in phrases functioning as subject or object in clause structure. Traditional grammar did not have a comparable category of NP and focused on the differences between pronouns and common or proper nouns rather than the functional likeness.

${ }^{2}$ In modern linguistics, the word phrase is distinct from the traditional notion of a group of words without a main verb and can in many situations be applied to a single word. For example, in it stopped, verb phrase (VP) consists of only the single word stopped.

${ }^{3}$ Huddleston (personal communication) suggested this terminology as being morehelpfully distinct than the determinative/determiner pair used in his book and elsewhere.

${ }^{4}$ For example, little, a little, and all and that.

${ }^{5}$ The genitive case is sometimes called possessive.

${ }^{6}$ Huddleston and Pullum (2002) use the term determiner for this function.

${ }^{7} \mathrm{NP}$ here does not include constituents such as infinitives and gerunds, which have often been said to function as nouns; noun is not a function.

${ }^{8}$ Some determinatives can be modified, so strictly speaking, we should say determinative phrases (DPs).

${ }^{9}$ Determinatives will not work in constructions like *little of water, where the NP is indefinite.

${ }^{10}$ They are also mutually exclusive with specifiers with the form of noun phrases, except that every is permitted after genitives: Jean's/her every move.

${ }^{11}$ Comparative and superlative adjectives can occur before of + DEFINITE NP, but only if preceded by a specifier: The better/best of the options is this one, not *Better/best of the options is this one.

${ }^{12}$ Celce-Murcia and Larsen-Freeman (1999), for example, departfromalmostallotherworksinincluding: a (good) number of, a lot of, a great deal of, a good deal of, a lot of (p. 330), which should simply be seen as D + (Adj) + N + of. See, for example, Carter and McCarthy (2006).

${ }^{13}$ A third type of error appears to be idiosyncratic. Batstone's Grammar (1994) uniquely and inexplicably presents it as a determiner.

${ }^{14}$ In an entry for possessive determiner in his Dictionary of English Grammar (2000), Trask writes: "Though traditional grammarclasses these as pronouns, they are not pronouns but determiners, since they behavelikedeterminers and notlike pronouns." Infact, traditional grammarhastypically classed these words as adjectives, not pronouns (e.g., Bloomfield's \& Palmer's quotations above).

${ }^{15}$ The Linnaeanhierarchy is kingdom $>$ phylum $>$ class $>$ order $>$ family $>$ genus $>$ species. Marsupials and placentals are subclasses of the class of mammals.

${ }^{16}$ These terms appear in the first printing of the book, but some have changed in more recent printings.

${ }^{17}$ Celce-Murcia and Larsen-Freeman (1999) acknowledge that "nouns marked with possessive inflection have two main uses: (1) they may be definite determiners ... or (2) they may be a modifier" (p. 313). Again, this makes sense only if determiner is a function term and not a category term and reinforces the idea that the category of genitive NPs is just that: NP. 
${ }^{18}$ Celce-Murcia and Larsen-Freeman are preparing a third edition of TGB which will contain some changes in its treatment of determiners (personal communication, April 13, 2011).

${ }^{19}$ According to Huddleston and Pullum (2002), the second many in fact combines the functions of specifier and head; the head is "fused" with the specifier. It is not necessary in this article to follow this analysis. The crucial point is that the head function is filled by many.

${ }^{20}$ As mentioned above, we/us and you are primarily pronouns but also exist as determinatives as in you boys or us kids.

${ }^{21}$ Of course, it is possible that there will also be unintended negative consequences.

\section{Acknowledgments}

Ithank VeraBeletzan, GretchenBoehlke, MarianneCelce-Murcia, LoriHabermehl,DianeLarsen-Freeman, and John Payne for their comments on earlier drafts of this article and especially acknowledge the extensive, detailed, and illuminating comments that I received from Rodney Huddleston.

\section{The Author}

BrettReynolds teachesin theSchool of Liberal Arts and Sciences, Humber Institute of Technology and Advanced Learning, Toronto.

\section{References}

Batstone, R. (1994). Grammar. Oxford, UK: Oxford University Press.

Bloomfield, L. (1933). Language. New York: Holt.

Breshears, S. (2004). Professionalization and exclusion in ESL teaching. TESL Canada Journal, Special Issue No. 4, 23-39.

Cambridge advanced learner's dictionary. (n.d.). Available: http:/ / dictionary.cambridge.org/ dictionary/british/

Carter, R., \& McCarthy, M. (2006). Cambridge grammar of English: A comprehensive guide to spoken and written English usage. Cambridge, UK: Cambridge University Press.

Celce-Murcia, M., \& Larsen-Freeman, D. (1999). The grammar book: An ESL/EFL teacher's course (2nd ed.). Boston, MA: Heinle \& Heinle.

Churcher, C.S. (1985). Dental functional morphology in the marsupial sabre-tooth Thylacosmilus atrox (Thylacosmilidae) compared to that of felid sabre-tooths. Australian Mammalogy, 8(3), 201-220.

Colbert, E.H. (1974). Lystrosaurus from Antarctica. American Museum Novitates, No. 2535, 1-44. Available:http:/ / digitallibrary.amnh.org/dspace/ bitstream/handle/2246/5462/N2535.pdf/ja$\mathrm{ja} /$ ? sequence $=1$

Collins free cobuild online dictionary for English learners. (n.d.). Available: http:/ / www. collinslanguage.com/ free-online-cobuild-ESL-dictionary.aspx

Cook, V.J. (1989). The relevance of grammar in the applied linguistics of language teaching. Trinity College Dublin Occasional Papers (No. 22). Available: http:/ / homepage.ntlworld.com/vivian.c/ Writings/Papers/TCD89.htm

Ellis, R. (1994). The study of second language acquisition. Oxford, UK: Oxford University Press.

Ellis, R. (2006). Current issues in the teaching of grammar: AnSLA perspective. TESOL Quarterly, 40, 83-107.

Halliday, M.A.K., \& Matthiessen, C. (2004). An introduction to functional grammar (3rd ed.). London: Arnold.

Halliday, M.A.K., McIntosh, A., \& Strevens, P. (1964). The linguistic sciences and language teaching. London: Longmans.

Huddleston, R. (1984). Introduction to the grammar of English. Cambridge, UK: Cambridge University Press. 
Huddleston, R., \& Pullum, G. K. (2002). The Cambridge grammar of the English language. Cambridge, UK: Cambridge University Press.

Longman dictionary of contemporary English online. (n.d.). Available: http:/ / www.ldoceonline.com/ Macmillan dictionary. (n.d.). Available: http:/ / www.macmillandictionary.com/

Mathews, P., \& Chuntian, C. (Eds.). (2004). Professionalism in teaching ESL in Canada and abroad. TESLCanadaJournal,SpecialIssue4.Available:http://journals.sfu.ca/tesl/index.php/tesl/issue/ view / 124

Merriam-Webster's learner's dictionary. (n.d.). Available: http:/ / www.learnersdictionary.com/

NationalEducation Association. (n.d.). CodeofEthics. Available:http:/ / www.nea.org/home/30442. htm

Onions, C.T. (1971). Modern English syntax. London: Routledge.

Oxford advanced learner's dictionary. (n.d.). Available: http:/ / www. oxfordadvancedlearnersdictionary.com/

Palmer, H.E. (1924). A grammar of spoken English on a strictly phonetic basis. Cambridge, UK: W. Heffer \& Sons.

Parrott, M. (2010). Grammar for English language teachers (2nd ed.). Cambridge, UK: Cambridge University Press.

Quirk, R., Greenbaum, S., Leech, G., \& Svartvik, J. (1985). A comprehensive grammar of the English language. London: Longman.

Radford, A. (2009). Transformational grammar: A first course. Cambridge, UK: Cambridge University Press.

Reppen, R. (2011). Grammar and beyond 2. Cambridge, UK: Cambridge University Press.

Sinclair, J. (Ed.). (1990). Collins COBUILD English grammar. London: Collins.

Swan, M. (2005). Practical English usage. Oxford, UK: Oxford University Press.

Trask, R.L. (2000). The Penguin dictionary of English grammar. London: Penguin.

Van Beuningen, C.G., De Jong, N.H., \& Kuiken, F. (2012). Evidence on the effectiveness of comprehensive error correction in second language writing. Language Learning, 62(1), 1-41.

Widdowson, H.G. (2000). On the limitations of linguistics applied. Applied Linguistics, 21(1), 3-25.

Williams, J.D. (2005). The teacher's grammar book (2nd ed.). Mahwah, NJ: Erlbaum.

Zimmer, C. (2010). The tangled bank: An introduction to evolution. Greenwood Village, CO: Roberts and Company. 